OPEN ACCESS

Edited by:

Cristina Poveda,

Baylor College of Medicine,

United States

Reviewed by:

Liliana Estefania Villanueva Lizama,

Universidad Autónoma de Yucatán,

Mexico

Francisco Callejas Hernández, New York University, United States

*Correspondence:

Lucia Mendonça-Previato luciamp@biof.ufrj.br

Leonardo Freire-de-Lima leolima@biof.ufrj.br Kelli Monteiro da Costa kellimc85@biof.ufr.br

${ }^{t}$ These authors have contributed equally to this work

Specialty section: This article was submitted to Parasite and Host, a section of the journal Frontiers in Cellular and Infection Microbiology

Received: 31 August 2021 Accepted: 12 October 2021 Published: 26 October 2021

Citation:

da Costa KM, Marques da Fonseca L, dos Reis JS, Santos MARdC, Previato JO, Mendonça-Previato $L$ and Freire-de-Lima L (2021)

Trypanosoma cruzi trans-Sialidase as a Potential Vaccine Target

Against Chagas Disease.

Front. Cell. Infect. Microbiol. 11:768450.

doi: 10.3389/fcimb.2021.768450

\section{Trypanosoma cruzi trans-Sialidase as a Potential Vaccine Target Against Chagas Disease}

\author{
Kelli Monteiro da Costa ${ }^{\dagger *}$, Leonardo Marques da Fonseca ${ }^{\dagger}$, Jhenifer Santos dos Reis, \\ Marcos André Rodrigues da Costa Santos, José Osvaldo Previato, \\ Lucia Mendonça-Previato* and Leonardo Freire-de-Lima* \\ Laboratório de Glicobiologia, Instituto de Biofísica Carlos Chagas Filho, Universidade Federal do Rio de Janeiro, Rio de \\ Janeiro, Brazil
}

Chagas' disease is caused by the protozoan Trypanosoma cruzi, described in the early $20^{\text {th }}$ century by the Brazilian physician Dr. Carlos Chagas. There was a great amount of research devoted to diagnosis, treatment and prevention of the disease. One of the most important discoveries made since then, impacting the understanding of how the parasite interacts with the host's immune system, was the description of trans-sialidase. It is an unique enzyme, capable of masking the parasite's presence from the host, while at the same time dampening the activation of CD8+ T cells, the most important components of the immune response. Since the description of Chagas' disease in 1909, extensive research has identified important events in the disease in order to understand the biochemical mechanism that modulates $T$. cruzi-host cell interactions and the ability of the parasite to ensure its survival. The importance of the trans-sialidase enzyme brought life to many studies for the design of diagnostic tests, drugs and vaccines. While many groups have been prolific, such efforts have encountered problems, among them: the fact that while $T$. cruzi have many genes that are unique to the parasite, it relies on multiple copies of them and the difficulty in providing epitopes that result in effective and robust immune responses. In this review, we aim to convey the importance of trans-sialidase as well as to provide a history, including the initial failures and the most promising successes in the chasing of a working vaccine for a disease that is endemic in many tropical countries, including Brazil.

Keywords: Trypanosoma cruzi, Chagas disease, sialic acid, trans-sialidase, vaccine 


\section{INTRODUCTION}

Chagas disease is an anthropozoonosis caused by the flagellated protozoan Trypanosoma cruzi. American trypanosomiasis received this name in honor of Dr. Carlos Chagas, who described in his work, in 1909, the etiologic agent of the disease, the evolutionary cycle of the parasite as well as the vectors and clinical manifestations of the acute phase (Chagas, 1909). According to the World Health Organization, Chagas disease is classified as a neglected tropical disease with an estimated 8 million people infected worldwide and almost 100 million at risk of infection, the majority being found in Latin America.

The main form of transmission is vector, predominant in rural areas with rudimentary infrastructure, promoting an environment favorable to the reproduction of vectors as well as proximity to the wild cycle (Bern et al., 2019). Due to prevention and chemical control policies adopted since 1975 by most Latin American countries cases of domestic vector transmission have decreased substantially, reducing the occupation and prevalence of the main vectors in these areas (WHO, 2017). Nonetheless, Chagas' disease is considered a reemerging infection due to alternative transmission routes of $T$. cruzi. One of them is the migration of asymptomatic infected individuals to non-endemic areas, allowing the transmission of the parasite via blood, organ or tissue donation, especially in countries that do not routinely search for T. cruzi in samples (Angheben et al., 2015). Another route occur through the consumption of food contaminated with both the feces of vectors and the secretion of infected mammals (Pereira et al., 2009). In these cases, individuals receive a high parasitic burden, which results in a more severe acute clinical manifestation with a high mortality rate (Yoshida et al., 2011).

In addition, the phenomenon of ecological succession allows new species to occupy niches previously occupied by removed ones, demonstrating that some species of triatomines are highly anthropophilic with a great capacity to adapt to new habitats. The increase of temperature has a direct effect on the development of vectors whose feed more frequently, putting more people at risk of infection (Short et al., 2017). This is a growing concerning in nonendemic areas as the southern United States of America, due to the increase in infestation of these insects in recent years. Even when serological testing for Chagas disease started in 2008 for blood donors in the state of Texas, seropositivity for T. cruzi was found in 1 in 6500 donors (Garcia et al., 2015b), with 5 of these cases being postulated as autochthonous transmission (Garcia et al., 2015a). Moreover, bedbugs (Cimex lectularius) may have an impact on the recent epidemiology of Chagas disease, since the species has been reported as a potential vector by sharing eating

\footnotetext{
Abbreviations: APC, antigen-presenting cells; CTL, cytotoxic T lymphocytes; GMDSC, granulocytic myeloid-derived suppressor cells; Ig, immunoglobulin; IMX, ISCOMATRIX; INF- $\gamma$, gamma interferon; iTS, inactive trans-sialidase; Mab, monoclonal antibodies; MDSC, myeloid-derived suppressor cells; M-MDSC, monocytic myeloid-derived suppressor cells; mTS, mutant trans-sialidase; SAPA, shed acute phase antigen; SCID, severe combined immunodeficiency; Sia, sialic acid; Th, T helper; Treg, Foxp3+ CD4+ T cells; TS, trans-sialidase; TSf, trans-sialidase fragment.
}

patterns similar and infecting mice both oral and vectorially (Salazar et al., 2015).

T. cruzi infection presents distinct two phases. The acute phase is characterized by high parasitemia, which can be asymptomatic, symptomatic and in rare cases fatal (Bern et al., 2019). Acute phase is recognized in only $2 \%$ of patients, since it is usually asymptomatic or displays non-specific symptoms (WHO, 2017). The absence of treatment results in the evolution to the chronic phase. In the indeterminate form, most individuals remain asymptomatic over the years, although they present positive serology for T. cruzi. However, about $30 \%$ of patients may progress to the determinate form of Chagas' disease, with cardiac, digestive or mixed clinical manifestations (Bern, 2015). Currently, there is no vaccine to prevent Chagas disease and chemotherapy is the only alternative for curing infected individuals. The success of treatment depends on stage of the disease, age of the patient and biochemical characteristics of the parasite strain (WHO, 2017). Benznidazole is the drug of first choice with a cure rate of approximately $80 \%$ when administered in the acute phase. In the chronic phase, its effectiveness is reduced, as the real benefits of the treatment are not clear since the damage to affected organs is irreversible (Bern et al., 2019; Francisco et al., 2020).

Protective vaccines against several microorganisms have contributed to public health policies, allowing the effective control of diseases such as rabies, polio, diphtheria, measles, smallpox and tetanus. However, there is an urgency for the designer of vaccines against several other microorganisms, mainly parasites that cause serious human infections and a great public expense, such as Chagas disease, Leishmaniasis and Malaria. The production of a vaccine emerges as an economically advantageous alternative due to the reduction of expenses with patients, as well as an alternative to the reduction in the number of deaths. In recent years, several groups have focused on the development of vaccines for different immunodominant epitopes found in T. cruzi. Here, we will focus on advances in trans-sialidase (TS) protein-based vaccines. Basically, immunization against infectious agents can be divided into whole cell, toxoid, subunit and virus-vectored vaccines (Delany et al., 2014). In the second-last group are protein-based vaccines, which are purified from the entire pathogen or produced by recombinant genetic engineering (Lee et al., 2018). In recent years, recombinant protein technology has become efficient, allowing for cost-effective production in bacteria, yeast and other expression systems (Francis, 2018). This type of vaccine is considered safer even in immunosuppressed individuals due to the lack of an infectious agent. However, they usually have low immunogenicity, requiring booster doses and/or the use of adjuvants (Vetter et al., 2018).

\section{TRANS-SIALIDASE AND ITS EFFECTS ON THE IMMUNE SYSTEM}

Out of all T. cruzi virulence factors, TS is likely the most important and by far the most interesting (Freire-De-Lima et al., 2015). It was 
already a known fact that T. cruzi would sport sialic acid (Sia) residues in the epimastigote's surface membrane (Pereira et al., 1980; Schauer et al., 1983), despite being incapable of synthetizing Sia by itself. Our group first described it in 1985, when Previato et al. proposed that T. cruzi was capable of incorporating Sia residues in $\alpha-2,3$ bonds to its own surface glycoproteins (Previato et al., 1985) thanks to TS activity in a mechanism that was later demonstrated both in vitro (Zingales et al., 1987; Schenkman et al., 1991) and in vivo (Previato et al., 1990).

The TS genes are part of the largest multigene superfamily in T. cruzi, composed of 1430 genes and 639 pseudogenes in the genome of the CL Brener strain (Herreros-Cabello et al., 2020). However, this number can vary considerably depending on the strain analysed (Berna et al., 2018; Callejas-Hernandez et al., 2018; Herreros-Cabello et al., 2020). Its members are currently divided into eight groups and all share the characteristic motif of the TS and TS-like superfamily: VTVxNVxLYNR (Freitas et al., 2011). Only proteins that clustered in group I present transsialidase and/or neuraminidase enzymatic activities and gave the superfamily its name. Most members from group I are formed by two main regions: $\mathrm{N}$-terminal catalytic region and $\mathrm{C}$-terminal one, containing repeating 12-amino acid sequences, known as Shed Acute Phase Antigen (SAPA), and GPI anchor (Pollevick et al., 1991). From its 19 members listed in the genome, the known members SAPA and TCNA are expressed in trypomastigotes and TS-epi, in epimastigotes (Freitas et al., 2011; Herreros-Cabello et al., 2020). The catalytic domain is rich in aromatic amino acids and a substitution mutation, with Tyrosine342 replaced by histidine being the most common, results in an inactive isoform of TS (iTS) (Cremona et al., 1995). iTS functions as a lectin capable of binding Sia residues (Todeschini et al., 2002a), and although it does not have catalytic properties, it must have a role during the cell invasion process (Freire-de-Lima et al., 2015). TS activity has been considered essential for parasite invasion and perpetuation in the infected host (Teixeira et al., 2015).

Regarding the other groups, group II comprises the genes of the known GP85 surface glycoproteins, such as ASP-1, ASP-2, TSA-1, Tc85, SA85, GP82, GP90, among others, which are expressed in trypomastigotes and associated with T. cruzi adhesion and invasion. Group III genes are also expressed in trypomastigotes and are able to inhibit the complement system, protecting T. cruzi from lysis. Known members include CRP, FL160, CEA and TESA. Group IV presents as a representative sequence TsTc13 and has no known function yet. Members of groups V to VIII have the gene sequence identified in the genome, but their function has not yet been described (Freitas et al., 2011; Callejas-Hernandez et al., 2018; Herreros-Cabello et al., 2020).

TS groups are defined by specific motifs, with group I being found in all T. cruzi strains and in different species of the genus (Herreros-Cabello et al., 2020). However, groups II and V are the most abundant in the genome of CL Brener (Freitas et al., 2011) and of other strains genome (Herreros-Cabello et al., 2020). The TS and TS-like superfamily have highly antigenic peptides, capable of eliciting a robust humoral response
(Freitas et al., 2011) and are vaccine candidates against Chagas disease, such as TSA-1 (De La Cruz et al., 2019; Dumonteil et al., 2020), ASP-1, ASP-2 (Garg and Tarleton, 2002) and CRP (Sepulveda et al., 2000) and others. Nonetheless, only group I members that exhibit enzymatic activity and are referred to here as TS protein are the focus of this review.

Throughout evolution, T. cruzi developed elegant mechanisms to disrupt the host immune response (Figure 1). Examples include its ability to induce anergy of T cells, as well as the production of low affinity antibodies (Oladiran and Belosevic, 2012; Nardy et al., 2016), which may be enabled by the action of TS proteins (Silva-Barrios et al., 2018; Da Fonseca et al., 2019). Since its discovery, several research groups have proposed molecular mechanisms displayed especially by the enzymatically active members to dampen the mammalian immune system, such as inducing apoptosis in thymocytes or even matures T lymphocytes (Mucci et al., 2002; Mucci et al., 2005) and also by dampening the ability of effector cells to combat the infection (Chuenkova and Pereira, 1995; Gao and Pereira, 2001; Gao et al., 2002; Freire-De-Lima et al., 2010; Bermejo et al., 2013; Nunes et al., 2013; Ruiz Diaz et al., 2015). In addition, given Sia's ubiquitous distribution in the surface of mammalian cell, and its importance for both innate and adaptive immunity, it is not at all surprising to see that a foreign enzyme capable of such modulation of Sia expression has such ability to modulate the host's immune system (Amon et al., 2014; Chen et al., 2014).

Our own group described how T. cruzi, due to TS activity is not only able to remove Sia from the host cells, but is also able to sialylate CD43 molecules present in the surface of T CD8 cytotoxic lymphocytes (Todeschini et al., 2002b; Mucci et al., 2006; Freire-De-Lima et al., 2010; Da Fonseca et al., 2019), this loss of Sia residues is one the necessary steps in the activation of these immune cells, since the presence of Sia prevents an effective interaction with MHC class I (Moody et al., 2001). Adding to that notion, the sialylation of CD43 in thymocytes by TS has been correlated to increased apoptosis in these immature cells, and not only that, but the use of TS inhibitors has been shown to halt the process (Mucci et al., 2006).

In a previous study, it was demonstrated that active TS induces the secretion of the cytokine IL-17 by B cells. Interestingly, such phenomenon was dependent on the sialylation of cell surface glycoconjugates, especially the CD45 glycoprotein (Bermejo et al., 2013). Although the mechanisms involved in many of those effects are not fully determined, it is clear they are dependent on the activity of T. cruzi TS, since they cannot be replicated by viral or bacterial neuraminidases and also, since TS does not affect mortality of SCID (severe combined immunodeficiency) mice, at least the main effects seem to involve mature host lymphocytes (Chuenkova and Pereiraperrin, 2005).

Given the many effects T. cruzi TS has on the host immune system and its importance to cell invasion, and adding the fact that there is no analogous enzyme in humans or other mammalian hosts, it does not come as a surprise that TS has always been considered a prime target for pharmacological intervention. Efforts to thwart TS effects in the immune system 


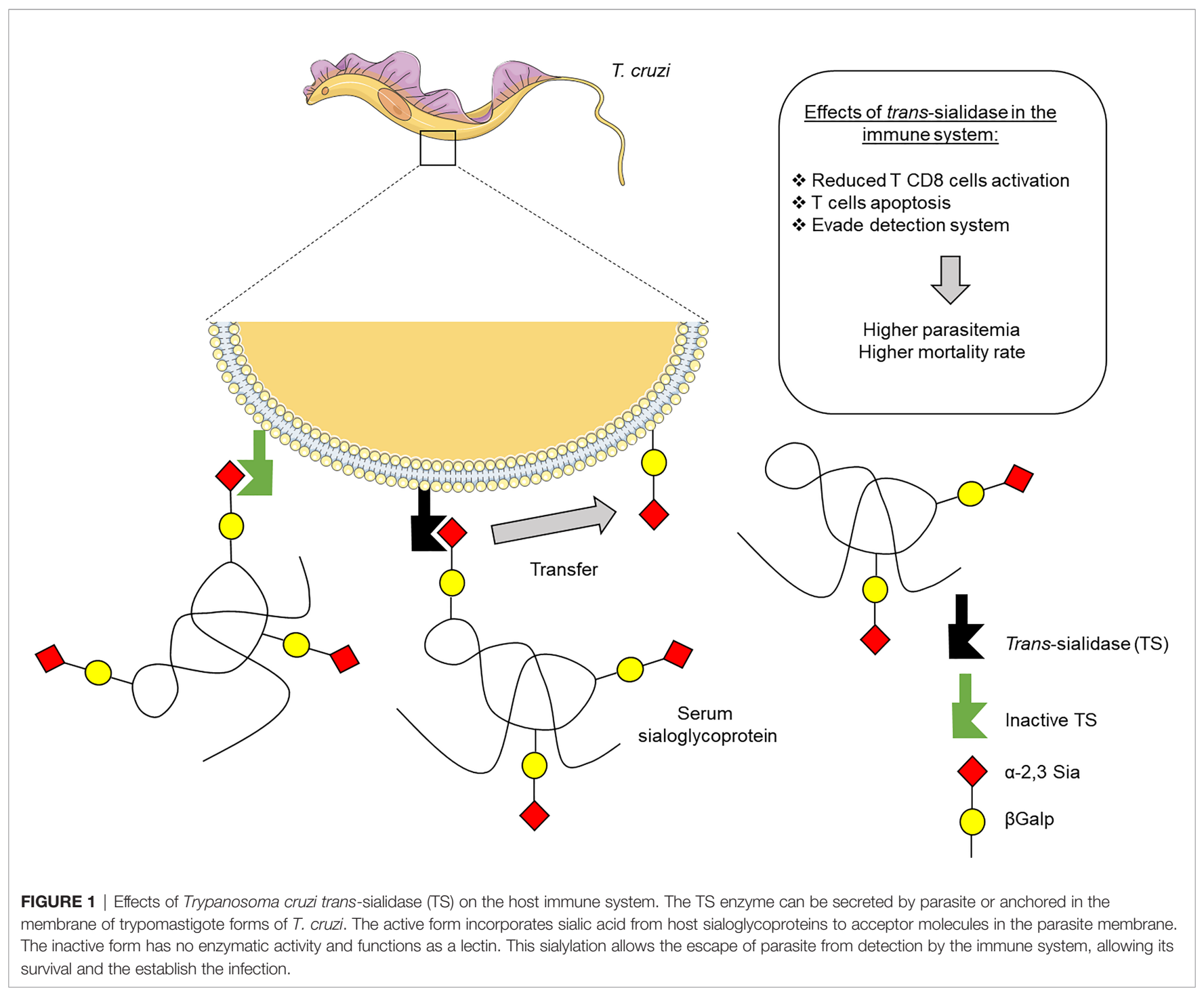

are not a recent novelty. Because sialoglycans play a crucial role in T. cruzi interaction and invasion events in host cells (Schenkman et al., 1993; Freire-De-Lima et al., 2017; Campetella et al., 2020), several groups, including ours, have searched for suitable strategies that could potentially be used to improve the outcome of Chagas patients. A previous study demonstrated that the use of neutralizing antibodies aimed at TS was effective in reducing parasitemia and mortality in mice, as well as preserved B cell areas both in ganglia and in spleen, and thymus architecture (Risso et al., 2007). Results published by our group confirmed the relevance of Sia on parasite-host cell contact from the use of a Vibrio cholerae neuraminidase suicide-type inhibitor (Carvalho et al., 2010). In this study, we demonstrated that besides inhibiting both TS and neuraminidase activities, the suicide-type inhibitor significantly reduced the parasite survival in T. cruzi-infected cells (Carvalho et al., 2010). In fact, over the last fifteen years, many natural and/or synthetic molecules have been tested as specific inhibitors (Buchini et al., 2008; Arioka et al., 2010; Carvalho et al., 2010; Giorgi et al., 2010; Lieke et al.,
2011; Chen et al., 2018; Vazquez-Jimenez et al., 2021) of T. cruziTS activity, aiming towards the discovery of new agents for the cure of Chagas' disease, but so far, a strong inhibitor has not been found. Since Sia cannot be synthesized by the parasite, and acts as an essential molecule for both communication and invasion of host cells, further studies are needed to better understand the catalytic mechanisms of the enzyme to favor the rational design of potential TS inhibitors.

\section{TRANS-SIALIDASE BASED VACCINE}

In 1912, Blanchard demonstrated that animals surviving acute infection with $T$. cruzi were resistant to reinfection. Since then, active immunization against Chagas disease has been investigated besides methods to prepare the parasite for inoculation. Later, Pizzi and Prager used for the first time the cultivated and attenuated forms of $T$. cruzi to induce immunization and protect animals from infection by virulent 
strains (Rodriguez-Morales et al., 2015). Currently, there are several vaccine formulations against Chagas disease tested in animal model in the pre-clinical phase. Dumonteil and Herrera listed the recent formulations and platforms against T. cruzi, being 8 therapeutic and 19 protective vaccines (Dumonteil and Herrera, 2021). However, no vaccine is in clinical phase according to data from the Clinicaltrials.gov website. The main candidates for vaccines against infectious diseases already in clinical studies are based on attenuated microorganisms, DNA, viral vectors and recombinant proteins. Although there are many vaccines in phase one of the clinical trial, only vaccines with attenuated microorganisms and recombinant proteins are advancing to phases two and three. Possibly because DNA vaccines have shown low immunological efficacy in humans, although several strategies are being investigated to increase their immunogenicity (Suschak et al., 2017). Vector vaccines present greater safety issues due to immune cross-reactivity with the vectors and, consequently, the presence of adverse effects (Delany et al., 2014). As a result of the particularities of $T$. cruzi subculture that has an obligatory intracellular cycle, vaccines with live parasites pose a challenge for large-scale production as well as storage and distribution. Thus, vaccine candidates with recombinant proteins present a more promising proposal for success against T. cruzi.

In the 1990s, the development of DNA vaccines against infections caused by Plasmodium yoelli (Sedegah et al., 1994) and Leishmania major (Xu and Liew, 1995) showed great results of immunogenicity. In 1998, a study addressed the question of whether DNA vaccination could elicit immunization against experimental T. cruzi infection using as antigen the enzyme TS (Costa et al., 1998). Possibly, the idea of using TS came from several evidences suggesting that this enzyme is a virulence factor involved in the establishment of the infection (Chuenkova and Pereira, 1995; Leguizamon et al., 1999; Mucci et al., 2002; Tribulatti et al., 2005). Furthermore, a year earlier, Franchin and collaborators demonstrated that the passive transfer of monoclonal antibodies (MAb) recognizing sialic acid-dependent epitopes on the surface of bloodstream trypomastigotes was able to reduce parasitemia and the number of T. cruzi parasites found in the heart, skeletal muscle and liver, increasing the survival of immunized and challenged animals (Franchin et al., 1997). This reduction was specific since the passive transfer of MAbs recognizing the C-terminal repeated region of the TS did not produce the same effects. Thus, Costa et al. demonstrated that active immunization with plasmid DNA for the catalytic domain of TS elicited protective activity against $T$. cruzi infection in BALB/C mice (Costa et al., 1998). The IgG1 antibody class is the predominant one detected in the serum of immunized mice, being able to inhibit TS activity in vitro. Similarly, mice actively immunized and subsequently challenged with bloodstream trypomastigotes had a reduction in peak parasitemia and mortality. Although the study did indeed evaluated as occurs this protective response, recombinant TS evoked a significant type IV hypersensitivity response, a unique type of mediated immunity cells, and induced an intense proliferation in lymphoid cells derived from the lymph node and spleen of immunized mice (Costa et al., 1998).

The following year, a study compared the effects of immunogenicity from plasmids containing the catalytic domain gene of T. cruzi TS and recombinant and native TS. Both forms of immunization produced a peak humoral response after 3-4 doses, having no additive effect with the administration of a fifth dose (Pereira-Chioccola et al., 1999). Any immunization originated from the recombinant as native TS produced ten times more antibody titers that performed TS plasmid. Again, the two forms of immunization produced antibodies capable of inhibiting TS activity in vitro, requiring lower concentrations of antibodies from immunization with the protein (PereiraChioccola et al., 1999). Unlike Costa et al.'s results (Costa et al., 1998), naked DNA immunization produced mostly IgG2a class antibodies that did not protect mice from death after challenge with T. cruzi. On the other hand, immunization with the recombinant protein mainly produced IgG1 antibodies and $60 \%$ of the immunized mice survived the infection (PereiraChioccola et al., 1999). Thus, the authors speculate that immunization with recombinant TS with aluminum as weak adjuvant generated a Th2-type immune response, while naked DNA immunization generated a Th1-type response. It is noteworthy the difference in the survival of animals immunized and challenged with the $\mathrm{Y}$ strain of T.cruzi compared to the study by Costa et al. (1998). However, this change may be due to the murine model used in the studies. The murine $\mathrm{A} / \mathrm{Sn}$ strain is more sensitive to $\mathrm{Y}$ strain infection than the BALB/C strain. The amount needed to kill most animals of the first lineage is less than 250 bloodstream trypomastigotes, while for the last strain, at least 1500 parasites are necessary (Costa et al., 1998; Pereira-Chioccola et al., 1999; Gamba et al., 2021). Later, another study confirmed this immunomodulatory duality in vaccine with DNA versus recombinant protein, demonstrating that the simultaneous administration of both types of immunization (DNA vaccination + recombinant protein) still induced a Th2 type response. However, when two doses of TS gene DNA vaccine were administered prior to vaccination with recombinant $\mathrm{TS}$, the response reverted to the Th1 type (Vasconcelos et al., 2003).

Cells from the lymph node of BALB/C mice vaccinated with the TS gene were characterized as gamma-interferon (INF- $\gamma$ )producing Th1-type CD4 T cells, with highly cytotoxic activity in vitro and capable of inhibiting the development of T. cruzi in infected macrophages (Rodrigues et al., 1999). Surprisingly, the production of Th2-type cytokines such as IL-4 and IL-10 has been identified in some CD4 T cell clones. Additionally, CD8 T cells derived from the spleen of the immunized animals showed uniform response mediated by cytotoxic T lymphocytes (CTL), which also secrete INF- $\gamma$ and induce lysis and DNA degradation of cells expressing TS (Rodrigues et al., 1999). Generally, vaccines that use naked DNA produce a Th1-type immunomodulatory response due to the presence of Cpg oligopeptides in bacterial plasmids (Klinman et al., 1997; Leclerc et al., 1997). Clearly, the TS gene induces predominantly Th1 type cells, but also induces 
Th2 type cells (Pereira-Chioccola et al., 1999; Rodrigues et al., 1999), being possible the coexistence of these two populations as verified in DNA vaccine models with other genes (Mor et al., 1995; Chow et al., 1998).

To unravel the immunodominant epitopes of this response, Martin and colleagues revealed that a single TS epitope was responsible for stimulating more than $30 \%$ of circulating INF- $\gamma$ producing CD8 $\mathrm{T}$ cells from C57BL/6 mice infected with Brazil strain T. cruzi (Martin et al., 2006). Factors that appear to contribute to immunodominance include abundance and expression kinetics, release of peptides by cellular proteases, peptide affinity for MHC and CD8 T cell repertoire. Interestingly, this immunodominance for a single epitope is extremely high, as the typical frequencies reported for the same assay range from $2-20 \%$ of $\mathrm{CD} 8 \mathrm{~T}$ cells from mice infected with other diseases (Murali-Krishna et al., 1998). This ability of CD8 $\mathrm{T}$ cells to respond to a pool of few epitopes has also been observed in patients chronically infected with $T$. cruzi (Martin et al., 2006). In contrast, peptides encoded by genes from cruzipains, mucin-associated surface proteins, $\beta$ galactofuranosyl transferase and gp63 proteins showed a 4 to 20 -fold lower frequency of stimulation of INF- $\gamma$-producing cells compared to TS epitopes, suggesting that specificity of epitopes of CD8 T responses in experimental T. cruzi infection is strongly dominant by peptides encoded by the TS family (Martin et al., 2006). However, Tzelepis et al. provide evidence that this could be explained by competition of T cells by APC, as mice infected simultaneously with two strains of parasites containing different immunodominant peptides generated maximal responses to both peptides (Tzelepis et al., 2008). The interpretation was that whether the peptides are presented by different APCs, the immunodominant pattern was disrupted. Thus, the immunodominance mechanism would be a mechanism used by the parasite to reduce the immune response and favor the progression to the chronic phase of the disease. Two years later, Rosemberg and colleagues induced simultaneous tolerance to two immunodominant $T$. cruzi epitopes in a resistant mouse strain. After infection, there was an increased susceptibility to infection, but the animals were still controlled and survived the infection (Rosenberg et al., 2010). The authors suggested that the response was mediated by $\mathrm{CD} 8 \mathrm{~T}$ cells specific for subdominant epitopes that would replace the immunodominant ones. Dominguez et al. demonstrate that induction of response to subdominant antigens provides some degree of protection, although it does not produce an optimal response compared to immunodominant epitopes (Dominguez et al., 2011). Consequently, an artificial amplification of the immune response to subdominant antigens could be a strategy to improve the immunity induced by vaccination, favoring the host.

Despite the immunodominance capacity of TS peptides to stimulate CD8 CTL in mice infected with T. cruzi (Martin et al., 2006), vaccines with recombinant TS produce a predominantly Th2 response with activation of CD4 T cells, although they can protect immunized mice (Pereira-Chioccola et al., 1999). Parasitic diseases such as Leishmaniasis, Malaria and Chagas disease induce a large CD8 T response that is crucial for the resolution of the infection (Belkaid et al., 2002; Morrot and Zavala, 2004). Likewise, a vaccine model that induces a strong activation of CD8 CTL appears to contribute to a satisfactory protective response (Dumonteil, 2009). Generally, immunization with protein subunits does not stimulate CD8 CTL, as exogenous antigens are absorbed by endocytosis by antigen-presenting cells (APC), generating epitopes that are processed and presented exclusively via MHC class II, recognized only by CD4 T cells. However, some APCs are able to perform an alternative mechanism of cross-presentation of exogenous antigens via MHC class I, priming CD8 CTL in a process known as crosspriming (Rock and Shen, 2005). It is suggested that parasitic infections, such as Chagas disease, the induction of a TCD8 response comes from immunodominant peptides that may be favored in cross-priming in relation to subdominant peptides (Dominguez et al., 2011). This would explain why CD8 T cells respond to only a reduced pool of TS peptides.

Hoft and collaborators synthesized a Cpg mixed TS vaccine (TS/Cpg) administered intranasal or intramuscularly that induced systemic immunity in BALB/C mice challenged with the Tulahuen strain of T. cruzi, producing TS-specific IgG antibodies and reducing the mortality of infected animals. Immunization with intranasal TS/CpG mobilized activation of CD4 Th1 cells, as well as CD8 CTL with potential crosspresentation of antigens by B cells (Hoft et al., 2007). Furthermore, previous immunization with TS/Cpg induced the production of IgA detected in fecal extracts and significantly reduced the number of viable parasites in draining gastric lymph nodes and recoverable molecular equivalents of parasite from the gastric epithelium after oral infection, demonstrating in addition to systemic protective immunity also mucosal immunity (Hoft et al., 2007). Intranasal administration of vaccines is even more advantageous since DNA vaccines are degraded and/or are not well absorbed via the mucosa.

For over 20 years, it has been discovered that TS gene vaccination induces Th1 immunity in mice and other laboratory animals (Dumonteil et al., 2012; Luna and Campos, 2020). However, these DNA vaccines have not advanced to the clinical trial phases, possibly because they are not as efficient or safe for testing in humans (Schalk et al., 2006; Hobernik and Bros, 2018). On the other hand, immunization with recombinant protein subunits associated with adjuvants is less disputed regarding safety, being better accepted for clinical trials by regulatory agencies (Dumonteil et al., 2012). Aware of these facts, Fontanella and collaborators designed a vaccine candidate with a mutant TS (mTS - enzymatically deficient containing the catalytic domain and without the SAPA repeats), which showed a great protective response to infection by the Tulahuen strain in $\mathrm{BALB} / \mathrm{C}$ mice in relation to those not immunized or immunized with recombinant TS (Fontanella et al., 2008). For the first time, an immunization protected $100 \%$ of the animals and prevented the development of tissue damage, especially in the myocardium. Knowing the role of TS in the pathogenesis of Chagas disease, the design of a mutant candidate enabled a more appropriate protective response, since animals immunized with recombinant TS and challenged still exhibited tissue 
inflammation in skeletal and cardiac muscle, moderate splenomegaly and changes in hematocrit (Fontanella et al., 2008). Anti-SAPA antibodies were not found in immunized animals; they are not protective and seem to be associated with tissue damage and humoral response delay (Fontanella et al., 2008). Although Freund's complete adjuvant (FCA) used in the work has an excellent performance, ensuring a mixed humoral and cellular response that is hardly surpassed by other adjuvants, FCA is not recommended for human use due to the injuries associated with its administration. Local necrosis and granulomatous inflammatory response are characteristics from FCA injection site (Stills, 2005).

With that in mind, Bontempi and colleagues used mTS with a new adjuvant called ISCOMATRIX (IMX), composed of saponin, cholesterol and phospholipids that combined form 40-50 nm like-cage structures. IMX was chosen due to the antigen trafficking more efficient and persistent to draining lymph nodes (up to seven days after injection). Moreover, it promotes epitope processing and addressing both via MHC class II, presenting to CD4 T cells and inducing a B cell response; and via MHC class I, facilitating the cross-priming of CD8 T cells (Baz Morelli et al., 2012). Thus, immunization with mTS-IMX equaled the effects with mTS-FCA in terms of TS-specific antibody production, avidity, type IV hypersensitivity response, Th1 profile, and reduction in mortality and tissue damage (Bontempi et al., 2015). Again, there was 100\% survival of mice immunized and challenged with $T$. cruzi, even with ten times more inoculated bloodstream trypomastigotes than in the work by Fontanela et al. (Fontanella et al., 2008). Additionally, splenocytes from immunized animals showed a production of INF- $\gamma$ five times greater than infected mice, in addition to the production of IL-10 that could be responsible for halting an exacerbated inflammatory response (Bontempi et al., 2015). Subsequently, immunization with mTS-IMX proved to be more efficient in inducing humoral and cellular responses when compared to other immunogenic proteins such as flagellar repetitive protein (which contains tandem repeats), tryparedoxin peroxidase (involved in the metabolic pathway) and cruzipain (involved in parasite invasion) using the same adjuvant (Bontempi et al., 2017).

Based on background of TS-based vaccines, Prochetto and collaborators engineered a new peptide of only 290 amino acids, missing the SAPA domain and the Nh2 terminal region, making it inactive (Prochetto et al., 2017). The reduced size of the TS fragment (TSf) would facilitate the development of vaccines, considering the expression of recombinant proteins in bacteria is improved when the size of the DNA sequences is less than 1000 base pairs (Makino et al., 2011). TSf showed 90\% identity with the mTS sequence, derived from random mutagenesis in yeast, which showed a robust humoral and cellular response with IMX adjuvant, protecting $100 \%$ of the infected animals (Bontempi et al., 2015). TSf also showed $92 \%$ identity against TS sequences indexed in GenBank from different strains of T. cruzi (Prochetto et al., 2017). In addition, TSf was formulated with a new adjuvant called ISPA, composed of $70 \mathrm{~nm}$-liposomes with a cage-like structure from phosphatidylcholine, cholesterol, sterylamine, tocopherol and saponin (Bertona et al., 2017). TSf-ISPA showed similar results to immunization with mTS-IMX promoting stimulation of several Th1 profile components. Interestingly, TSf-ISPA immunized mice challenged with $T$. cruzi showed an increase of regulatory $\mathrm{T}$ splenocytes (Treg, CD4+Foxp3+) compared to non-immunized and challenged mice, although there was no change in the percentage of the population (Prochetto et al., 2017). Treg cells constitute about 3$5 \%$ of the peripheral $\mathrm{T}$ cell population and have an important anti-inflammatory activity for the regulation of immune homeostasis (Richards et al., 2015). The authors believe that this increase has a beneficial effect on the survival of immunized animals and, possibly, in the chronic phase of Chagas disease, taking into account that asymptomatic patients have a greater number of Treg cells than symptomatic patients. On the other hand, immunization reduced the percentage and absolute number of myeloid-derived suppressor cells (MDSC), heterogeneous population of immature innate cells composed of monocytes, granulocytes and dendritic cells expressing CD11b and GR-1 in mice, able to potently suppress pro-inflammatory immune responses (Yaseen et al., 2021). In the proposed model by authors, the formulation with TSf-ISPA generates a better control of the inflammatory response induced by components of the Th1 response, increasing protective FoxP3 Treg cells and reducing MDSC-induced generalized immunosuppression (Prochetto et al., 2017).

Some infection studies have shown an improvement in the vaccine response associated with a reduction in MDSC (Sui et al., 2014; Prochetto et al., 2017; Dorhoi et al., 2020). Recently, Gamba and collaborators decided to evaluate the role of MDSC cell depletion by 5 -fluoracil in the vaccine model with TSf-ISPA. The depletion of MDSC cells in BALB/C, 15 days after infection with T. cruzi, promoted an increase in parasitemia and $100 \%$ of the animals died by day 21 , even with a lower infective dose of the Tulahuen strain (900 bloodstream trypomastigotes). This result is possibly due to an exacerbated pro-inflammatory response by CD $8 \mathrm{~T}$ cells. In contrast, $60-100 \%$ of mice survived the challenge when they were previously immunized with TSfISPA, even with an almost complete reduction of the granulocytic population (G-MDSC) and partial reduction of the monocytic population (M-MDSC). These animals showed an increase in CD8 T cells, Treg cells and maturation of CD8 dendritic cells greater than mice immunized only and challenged with parasites, suggesting that modulation of MDSC cells may have beneficial effects on immunization against $T$. cruzi. Noteworthy, when MDSC depletion was early in immunized animals (day 5 post-infection or pre-immunization), there was a reduction in parasitemia and an increase in the survival of animals than late depletion (day 15 post-infection), even at lethal doses of T. cruzi (1500 bloodstream trypomastigotes) (Gamba et al., 2021) As a result, the possibility of modulating MDSC could be an interesting tool for the design of vaccines and adjuvants in TS-based vaccines.

The difficulty in producing vaccines when talking about Chagas disease is due to many factors. One of them is the great genetic and biochemical variability of the different strains 
of T. cruzi (Zingales, 2018). Since 2009, T. cruzi strains have been classified into six discrete typing units (DTU): I and II would be ancestral strains; III and IV, homozygous hybrids of ancestral strains; and V and VI, heterozygous hybrids of II and III (Zingales et al., 2009). TcBat is a new strain discovered in bats and has been considered as DTU VII (Lima et al., 2015). Breniere and collaborators provided an inventory with 6343 DTU analyzed according to geographic region and host origin. Although T. cruzi is considered a diploid organism, it presents variations in size and number of chromosomes between strains and within the same clone, demonstrating great genomic plasticity (Reis-Cunha et al., 2018). The TS family genes are part of the non-systemic disruptive compartment and are considered recent and still evolving. Possibly, its location close to telomeric and sub-telomeric regions favors genetic variability of this family due to the occurrence of recombination events (Chiurillo et al., 2016; Ramirez, 2019). This could generate a pool of different phenotypes within the same population and increase adaptability to different selective pressures, such as the evasion capacity of the immune system (Herreros-Cabello et al., 2020). In addition, the parasite has different evolutionary stages in host cells, expressing different patterns of surface glycoproteins that make it difficult for the host antibodies to recognize antigens. Additionally, the parasite has a great capacity to subvert pro- inflammatory immune responses using dual mechanisms to allow its permanence in the host (Cardoso et al., 2015; Da Fonseca et al., 2019). Therefore, these factors must be taken into account when developing TS-based vaccines.

The success of a recombinant TS vaccine for T. cruzi depends on its ability to produce an epitope-specific humoral response that experiences little variability between strains. As it is an exogenous protein, its antigens will be processed by APC and presented via MHC class II, recognized by CD4 T cells, which will induce stimulation of antibody-producing B cells. Certain types of APC can perform cross-presentation of antigens via MHC class I, recognized by CD8 T cells (Figure 2). This crosspresentation is enhanced with the use of a new generation of adjuvants as IMX and ISPA, being essential for a long-lasting protective response in subunit vaccine. Furthermore, these new adjuvants showed rapid and persistent antigenic delivery to APC as well as a robust Th1 response similar to FCA without causing adverse effects on immunization, making them safer for testing in humans. Moreover, it is normal for antibody titers to decrease over time in immunized and unstimulated individuals, reinforcing the contribution that cellular response can make at the onset of infection. However, an exacerbated inflammatory response can induce intense tissue inflammation, producing unwanted clinical manifestations. Thus, vaccine candidates

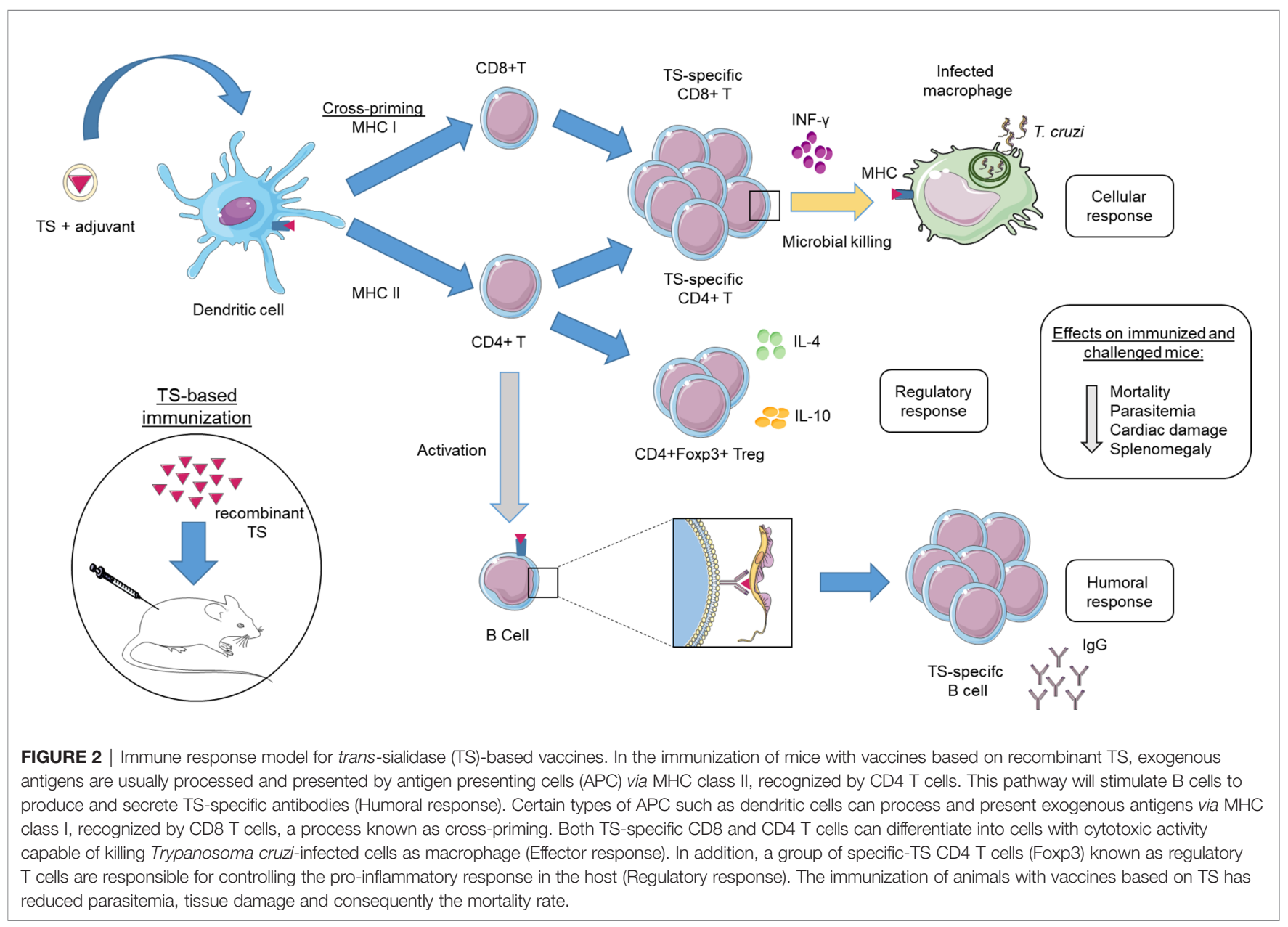


need to have a brake on the pro-inflammatory response. This function seems to be performed by the Treg cells in a murine model, which can be stimulated by reducing the MDSC population. As reported in the text, TS-based candidates have achieved high survival rates in animal model and reduced parasitemia. The increase in survival is essential but reducing the number of parasites is also an important parameter because it is associated with reduction of clinical symptoms in the chronic phase.

The development of recombinant vaccines against Chagas disease, in addition to focusing on sequences that present great immunogenicity, should overcome the problem of the great genetic variability of the strains. An inventory with 6343 strains divided into the six existing DTUs according to their geographic location and host origin showed that strains belonging to DTU I are more frequent (found in more than $60 \%$ of the analyzed samples) and widely distributed geographically (Breniere et al., 2016). Moreover, they cause the clinical manifestation of cardiac disease, with high morbidity, and are also found in patients infected by the oral route (Zingales et al., 2012; Zingales, 2018). For this reason, vaccines may initially focus on DTU I strains due to their epidemiological impact. Regarding the TS multigene family, group I presents the characteristic sequences of the family (VTVxNVxLYNR) and other conserved sequences such as Asp-box (SxDxGxTW) and SAPA that must be taken into

\section{REFERENCES}

Amon, R., Reuven, E. M., Leviatan Ben-Arye, S., and Padler-Karavani, V. (2014). Glycans in Immune Recognition and Response. Carbohydr. Res. 389, 115-122. doi: 10.1016/j.carres.2014.02.004

Angheben, A., Boix, L., Buonfrate, D., Gobbi, F., Bisoffi, Z., Pupella, S., et al. (2015). Chagas Disease and Transfusion Medicine: A Perspective From Non-Endemic Countries. Blood Transfus. 13, 540-550. doi: 10.2450/2015.0040-15

Arioka, S., Sakagami, M., Uematsu, R., Yamaguchi, H., Togame, H., Takemoto, H., et al. (2010). Potent Inhibitor Scaffold Against Trypanosoma Cruzi TransSialidase. Bioorg. Med. Chem. 18, 1633-1640. doi: 10.1016/j.bmc.2009.12.062

Baz Morelli, A., Becher, D., Koernig, S., Silva, A., Drane, D., and Maraskovsky, E. (2012). ISCOMATRIX: A Novel Adjuvant for Use in Prophylactic and Therapeutic Vaccines Against Infectious Diseases. J. Med. Microbiol. 61, 935-943. doi: 10.1099/jmm.0.040857-0

Belkaid, Y., Von Stebut, E., Mendez, S., Lira, R., Caler, E., Bertholet, S., et al. (2002). CD8+ T Cells Are Required for Primary Immunity in C57BL/6 Mice Following Low-Dose, Intradermal Challenge With Leishmania Major. J. Immunol. 168, 3992-4000. doi: 10.4049/jimmunol.168.8.3992

Bermejo, D. A., Jackson, S. W., Gorosito-Serran, M., Acosta-Rodriguez, E. V., Amezcua-Vesely, M. C., Sather, B. D., et al. (2013). Trypanosoma Cruzi TransSialidase Initiates a Program Independent of the Transcription Factors RORgammat and Ahr That Leads to IL-17 Production by Activated B Cells. Nat. Immunol. 14, 514-522. doi: 10.1038/ni.2569

Bern, C. (2015). Chagas' Disease. N. Engl. J. Med. 373. doi: 10.1056/NEJMra1410150

Berna, L., Rodriguez, M., Chiribao, M. L., Parodi-Talice, A., Pita, S., Rijo, G., et al. (2018). Expanding an Expanded Genome: Long-Read Sequencing of Trypanosoma Cruzi. Microb. Genom. 4, 1-19. doi: 10.1099/mgen.0.000177

Bern, C., Messenger, L. A., Whitman, J. D., and Maguire, J. H. (2019). Chagas Disease in the United States: A Public Health Approach. Clin. Microbiol. Rev. 33:1-42. doi: 10.1128/CMR.00023-19

Bertona, D., Pujato, N., Bontempi, I., Gonzalez, V., Cabrera, G., Gugliotta, L., et al. (2017). Development and Assessment of a New Cage-Like Particle Adjuvant. J. Pharm. Pharmacol. 69, 1293-1303. doi: 10.1111/jphp.12768 account in the design of the recombinant vaccine (Berna et al., 2018). It is noteworthy that similarities were found between the sequence of group I members of the T. cruzi TS with other species of the genus (Herreros-Cabello et al., 2020), suggesting the possibility of highly conserved sequences. In this way, we hope to have listed the strengths and weaknesses of TS-based vaccines and we believe that this protein due to its immunogenicity and conserved sequences still constitutes a great target to produce of a vaccine based on recombinant proteins that are cost effective on large scales and are safer when compared to other formulations.

\section{AUTHOR CONTRIBUTIONS}

KC and LM searched the bibliographic materials, reviewed the existing literature, and wrote the article. JR and MS reviewed the literature. LFL, JP, and LMP supervised the work. All authors contributed to the article and approved the submitted version.

\section{FUNDING}

The study was supported by Fundação Carlos Chagas Filho de Amparo à Pesquisa do Estado do Rio de Janeiro and Conselho Nacional de Desenvolvimento Científico e Tecnológico.

Bontempi, I., Fleitas, P., Poato, A., Vicco, M., Rodeles, L., Prochetto, E., et al. (2017). Trans-Sialidase Overcomes Many Antigens to be Used as a Vaccine Candidate Against Trypanosoma Cruzi. Immunotherapy 9, 555-565. doi: 10.2217/imt-2017-0009

Bontempi, I. A., Vicco, M. H., Cabrera, G., Villar, S. R., Gonzalez, F. B., Roggero, E. A., et al. (2015). Efficacy of a Trans-Sialidase-ISCOMATRIX Subunit Vaccine Candidate to Protect Against Experimental Chagas Disease. Vaccine 33, 1274 1283. doi: 10.1016/j.vaccine.2015.01.044

Breniere, S. F., Waleckx, E., and Barnabe, C. (2016). Over Six Thousand Trypanosoma Cruzi Strains Classified Into Discrete Typing Units (DTUs): Attempt at an Inventory. PloS Negl. Trop. Dis. 10, e0004792. doi: 10.1371/ journal.pntd.0004792

Buchini, S., Buschiazzo, A., and Withers, S. G. (2008). A New Generation of Specific Trypanosoma Cruzi Trans-Sialidase Inhibitors. Angew. Chem. Int. Ed Engl. 47, 2700-2703. doi: 10.1002/anie.200705435

Callejas-Hernandez, F., Rastrojo, A., Poveda, C., Girones, N., and Fresno, M. (2018). Genomic Assemblies of Newly Sequenced Trypanosoma Cruzi Strains Reveal New Genomic Expansion and Greater Complexity. Sci. Rep. 8, 14631. doi: 10.1038/s41598-018-32877-2

Campetella, O., Buscaglia, C. A., Mucci, J., and Leguizamon, M. S. (2020). ParasiteHost Glycan Interactions During Trypanosoma Cruzi Infection: TransSialidase Rides the Show. Biochim. Biophys. Acta Mol. Basis Dis. 1866, 165692. doi: 10.1016/j.bbadis.2020.165692

Cardoso, M. S., Reis-Cunha, J. L., and Bartholomeu, D. C. (2015). Evasion of the Immune Response by Trypanosoma Cruzi During Acute Infection. Front. Immunol. 6, 659. doi: 10.3389/fimmu.2015.00659

Carvalho, S. T., Sola-Penna, M., Oliveira, I. A., Pita, S., Goncalves, A. S., Neves, B. C., et al. (2010). A New Class of Mechanism-Based Inhibitors for Trypanosoma Cruzi Trans-Sialidase and Their Influence on Parasite Virulence. Glycobiology 20, 1034-1045. doi: 10.1093/glycob/cwq065

Chagas, C. (1909). Nova Tripanosomiase Humana. Estudos Sobre a Morfologia E O Ciclo Evolutivo do Schizotrypanum Cruzi N.G., N.Sp., Agente Etiológico De Nova Entidade Mórbida No Homem. Memórias do Instituto Oswaldo Cruz 1, 159-218. doi: 10.1590/S0074-02761909000200008 
Chen, G. Y., Brown, N. K., Zheng, P., and Liu, Y. (2014). Siglec-G/10 in SelfNonself Discrimination of Innate and Adaptive Immunity. Glycobiology 24, 800-806. doi: 10.1093/glycob/cwu068

Chen, Z., Marce, P., Resende, R., Alzari, P. M., Frasch, A. C., Van Den Elsen, J. M. H., et al. (2018). The Synthesis and Kinetic Evaluation of Aryl AlphaAminophosphonates as Novel Inhibitors of T. Cruzi Trans-Sialidase. Eur. J. Med. Chem. 158, 25-33. doi: 10.1016/j.ejmech.2018.08.089

Chiurillo, M. A., Moraes Barros, R. R., Souza, R. T., Marini, M. M., Antonio, C. R., Cortez, D. R., et al. (2016). Subtelomeric I-SceI-Mediated Double-Strand Breaks Are Repaired by Homologous Recombination in Trypanosoma Cruzi. Front. Microbiol. 7, 2041. doi: 10.3389/fmicb.2016.02041

Chow, Y. H., Chiang, B. L., Lee, Y. L., Chi, W. K., Lin, W. C., Chen, Y. T., et al. (1998). Development of Th1 and Th2 Populations and the Nature of Immune Responses to Hepatitis B Virus DNA Vaccines can be Modulated by Codelivery of Various Cytokine Genes. J. Immunol. 160, 1320-1329.

Chuenkova, M., and Pereira, M. E. (1995). Trypanosoma Cruzi Trans-Sialidase: Enhancement of Virulence in a Murine Model of Chagas' Disease. J. Exp. Med. 181, 1693-1703. doi: 10.1084/jem.181.5.1693

Chuenkova, M. V., and Pereiraperrin, M. (2005). A Synthetic Peptide Modeled on PDNF, Chagas' Disease Parasite Neurotrophic Factor, Promotes Survival and Differentiation of Neuronal Cells Through TrkA Receptor. Biochemistry 44, 15685-15694. doi: 10.1021/bi0512039

Costa, F., Franchin, G., Pereira-Chioccola, V. L., Ribeirao, M., Schenkman, S., and Rodrigues, M. M. (1998). Immunization With a Plasmid DNA Containing the Gene of Trans-Sialidase Reduces Trypanosoma Cruzi Infection in Mice. Vaccine 16, 768-774. doi: 10.1016/S0264-410X(97)00277-6

Cremona, M. L., Sanchez, D. O., Frasch, A. C., and Campetella, O. (1995). A Single Tyrosine Differentiates Active and Inactive Trypanosoma Cruzi TransSialidases. Gene 160, 123-128. doi: 10.1016/0378-1119(95)00175-6

Da Fonseca, L. M., Da Costa, K. M., Chaves, V. S., Freire-De-Lima, C. G., Morrot, A., Mendonca-Previato, L., et al. (2019). Theft and Reception of Host Cell's Sialic Acid: Dynamics of Trypanosoma Cruzi Trans-Sialidases and Mucin-Like Molecules on Chagas' Disease Immunomodulation. Front. Immunol. 10, 164. doi: 10.3389/fimmu.2019.00164

De La Cruz, J. J., Villanueva-Lizama, L., Dzul-Huchim, V., Ramirez-Sierra, M. J., Martinez-Vega, P., Rosado-Vallado, M., et al. (2019). Production of Recombinant TSA-1 and Evaluation of Its Potential for the ImmunoTherapeutic Control of Trypanosoma Cruzi Infection in Mice. Hum. Vaccin. Immunother. 15, 210-219. doi: 10.1080/21645515.2018.1520581

Delany, I., Rappuoli, R., and De Gregorio, E. (2014). Vaccines for the 21st Century. EMBO Mol. Med. 6, 708-720. doi: 10.1002/emmm.201403876

Dominguez, M. R., Silveira, E. L., De Vasconcelos, J. R., De Alencar, B. C., Machado, A. V., Bruna-Romero, O., et al. (2011). Subdominant/cryptic CD8 T Cell Epitopes Contribute to Resistance Against Experimental Infection With a Human Protozoan Parasite. PloS One 6, e22011. doi: 10.1371/journal.pone. 0022011

Dorhoi, A., Kotze, L. A., Berzofsky, J. A., Sui, Y., Gabrilovich, D. I., Garg, A., et al. (2020). Therapies for Tuberculosis and AIDS: Myeloid-Derived Suppressor Cells in Focus. J. Clin. Invest. 130, 2789-2799. doi: 10.1172/JCI136288

Dumonteil, E. (2009). Vaccine Development Against Trypanosoma Cruzi and Leishmania Species in the Post-Genomic Era. Infect. Genet. Evol. 9, 1075-1082. doi: 10.1016/j.meegid.2009.02.009

Dumonteil, E., Bottazzi, M. E., Zhan, B., Heffernan, M. J., Jones, K., Valenzuela, J. G., et al. (2012). Accelerating the Development of a Therapeutic Vaccine for Human Chagas Disease: Rationale and Prospects. Expert Rev. Vaccines 11, 1043-1055. doi: 10.1586/erv.12.85

Dumonteil, E., and Herrera, C. (2021). The Case for the Development of a Chagas Disease Vaccine: Why? How? When? Trop. Med. Infect. Dis. 6, 1-14. doi: 10.3390/tropicalmed6010016

Dumonteil, E., Herrera, C., Tu, W., Goff, K., Fahlberg, M., Haupt, E., et al. (2020). Safety and Immunogenicity of a Recombinant Vaccine Against Trypanosoma Cruzi in Rhesus Macaques. Vaccine 38, 4584-4591. doi: 10.1016/ j.vaccine.2020.05.010

Fontanella, G. H., De Vusser, K., Laroy, W., Daurelio, L., Nocito, A. L., Revelli, S., et al. (2008). Immunization With an Engineered Mutant Trans-Sialidase Highly Protects Mice From Experimental Trypanosoma Cruzi Infection: A Vaccine Candidate. Vaccine 26, 2322-2334. doi: 10.1016/j.vaccine.2008. 02.060
Franchin, G., Pereira-Chioccola, V. L., Schenkman, S., and Rodrigues, M. M. (1997). Passive Transfer of a Monoclonal Antibody Specific for a Sialic AcidDependent Epitope on the Surface of Trypanosoma Cruzi Trypomastigotes Reduces Infection in Mice. Infect. Immun. 65, 2548-2554. doi: 10.1128/ iai.65.7.2548-2554.1997

Francis, M. J. (2018). Recent Advances in Vaccine Technologies. Vet. Clin. North Am. Small Anim. Pract. 48, 231-241. doi: 10.1016/j.cvsm.2017.10.002

Francisco, A. F., Jayawardhana, S., Olmo, F., Lewis, M. D., Wilkinson, S. R., Taylor, M. C., et al. (2020). Challenges in Chagas Disease Drug Development. Molecules 25:1-14. doi: 10.3390/molecules25122799

Freire-De-Lima, L., Alisson-Silva, F., Carvalho, S. T., Takiya, C. M., Rodrigues, M. M., Dosreis, G. A., et al. (2010). Trypanosoma Cruzi Subverts Host Cell Sialylation and may Compromise Antigen-Specific CD8+ T Cell Responses. J. Biol. Chem. 285, 13388-13396. doi: 10.1074/jbc.M109.096305

Freire-De-Lima, L., Fonseca, L. M., Oeltmann, T., Mendonca-Previato, L., and Previato, J. O. (2015). The Trans-Sialidase, the Major Trypanosoma Cruzi Virulence Factor: Three Decades of Studies. Glycobiology 25, 1142-1149. doi: 10.1093/glycob/cwv057

Freire-De-Lima, L., Gentile, L. B., Da Fonseca, L. M., Da Costa, K. M., Santos Lemos, J., Jacques, L. R., et al. (2017). Role of Inactive and Active Trypanosoma Cruzi Trans-Sialidases on T Cell Homing and Secretion of Inflammatory Cytokines. Front. Microbiol. 8, 1307. doi: 10.3389/fmicb.2017.01307

Freitas, L. M., Dos Santos, S. L., Rodrigues-Luiz, G. F., Mendes, T. A., Rodrigues, T. S., Gazzinelli, R. T., et al. (2011). Genomic Analyses, Gene Expression and Antigenic Profile of the Trans-Sialidase Superfamily of Trypanosoma Cruzi Reveal an Undetected Level of Complexity. PloS One 6, e25914. doi: 10.1371/ journal.pone.0025914

Gamba, J. C., Roldan, C., Prochetto, E., Lupi, G., Bontempi, I., Poncini, C. V., et al. (2021). Targeting Myeloid-Derived Suppressor Cells to Enhance a TransSialidase-Based Vaccine Against Trypanosoma Cruzi. Front. Cell Infect. Microbiol. 11, 671104. doi: 10.3389/fcimb.2021.671104

Gao, W., and Pereira, M. A. (2001). Trypanosoma Cruzi Trans-Sialidase Potentiates T Cell Activation Through Antigen-Presenting Cells: Role of IL6 and Bruton's Tyrosine Kinase. Eur. J. Immunol. 31, 1503-1512. doi: 10.1002/ 1521-4141(200105)31:5<1503::AID-IMMU1503>3.0.CO;2-W

Gao, W., Wortis, H. H., and Pereira, M. A. (2002). The Trypanosoma Cruzi Trans-Sialidase Is a T Cell-Independent B Cell Mitogen and an Inducer of Non-Specific Ig Secretion. Int. Immunol. 14, 299-308. doi: 10.1093/intimm/ 14.3.299

Garcia, M. N., Aguilar, D., Gorchakov, R., Rossmann, S. N., Montgomery, S. P., Rivera, H., et al. (2015a). Evidence of Autochthonous Chagas Disease in Southeastern Texas. Am. J. Trop. Med. Hyg. 92, 325-330. doi: 10.4269/ ajtmh.14-0238

Garcia, M. N., Woc-Colburn, L., Aguilar, D., Hotez, P. J., and Murray, K. O. (2015b). Historical Perspectives on the Epidemiology of Human Chagas Disease in Texas and Recommendations for Enhanced Understanding of Clinical Chagas Disease in the Southern United States. PloS Negl. Trop. Dis. 9, e0003981. doi: 10.1371/journal.pntd.0003981

Garg, N., and Tarleton, R. L. (2002). Genetic Immunization Elicits AntigenSpecific Protective Immune Responses and Decreases Disease Severity in Trypanosoma Cruzi Infection. Infect. Immun. 70, 5547-5555. doi: 10.1128/ IAI.70.10.5547-5555.2002

Giorgi, M. E., Ratier, L., Agusti, R., Frasch, A. C., and De Lederkremer, R. M. (2010). Synthesis of PEGylated Lactose Analogs for Inhibition Studies on T.cruzi Trans-Sialidase. Glycoconj. J. 27, 549-559. doi: 10.1007/s10719-0109300-7

Herreros-Cabello, A., Callejas-Hernandez, F., Girones, N., and Fresno, M. (2020). Trypanosoma Cruzi Genome: Organization, Multi-Gene Families, Transcription, and Biological Implications. Genes (Basel) 11, 1-26. doi: 10.3390/genes11101196

Hobernik, D., and Bros, M. (2018). DNA Vaccines-How Far From Clinical Use? Int. J. Mol. Sci. 19, 1-28. doi: 10.3390/ijms19113605

Hoft, D. F., Eickhoff, C. S., Giddings, O. K., Vasconcelos, J. R., and Rodrigues, M. M. (2007). Trans-Sialidase Recombinant Protein Mixed With CpG MotifContaining Oligodeoxynucleotide Induces Protective Mucosal and Systemic Trypanosoma Cruzi Immunity Involving CD8+ CTL and B Cell-Mediated Cross-Priming. J. Immunol. 179, 6889-6900. doi: 10.4049/jimmunol. 179.10 .6889 
Klinman, D. M., Yamshchikov, G., and Ishigatsubo, Y. (1997). Contribution of CpG Motifs to the Immunogenicity of DNA Vaccines. J. Immunol. 158, 36353639.

Leclerc, C., Deriaud, E., Rojas, M., and Whalen, R. G. (1997). The Preferential Induction of a Th1 Immune Response by DNA-Based Immunization Is Mediated by the Immunostimulatory Effect of Plasmid DNA. Cell Immunol. 179, 97-106. doi: 10.1006/cimm.1997.1161

Lee, J., Arun Kumar, S., Jhan, Y. Y., and Bishop, C. J. (2018). Engineering DNA Vaccines Against Infectious Diseases. Acta Biomater. 80, 31-47. doi: 10.1016/ j.actbio.2018.08.033

Leguizamon, M. S., Mocetti, E., Garcia Rivello, H., Argibay, P., and Campetella, O. (1999). Trans-Sialidase From Trypanosoma Cruzi Induces Apoptosis in Cells From the Immune System In Vivo. J. Infect. Dis. 180, 1398-1402. doi: 10.1086/ 315001

Lieke, T., Grobe, D., Blanchard, V., Grunow, D., Tauber, R., ZimmermannKordmann, M., et al. (2011). Invasion of Trypanosoma Cruzi Into Host Cells Is Impaired by N-Propionylmannosamine and Other $\mathrm{N}$ Acylmannosamines. Glycoconj. J. 28, 31-37. doi: 10.1007/s10719-010-9321-2

Lima, L., Espinosa-Alvarez, O., Ortiz, P. A., Trejo-Varon, J. A., Carranza, J. C., Pinto, C. M., et al. (2015). Genetic Diversity of Trypanosoma Cruzi in Bats, and Multilocus Phylogenetic and Phylogeographical Analyses Supporting Tcbat as an Independent DTU (Discrete Typing Unit). Acta Trop. 151, 166-177. doi: 10.1016/j.actatropica.2015.07.015

Luna, E. J. A., and Campos, S. (2020). Vaccine Development Against Neglected Tropical Diseases. Cad. Saude Publica 36Suppl 2, e00215720. doi: 10.1590/ 0102-311X00215720

Makino, T., Skretas, G., and Georgiou, G. (2011). Strain Engineering for Improved Expression of Recombinant Proteins in Bacteria. Microb. Cell Fact 10, 32. doi: 10.1186/1475-2859-10-32

Martin, D. L., Weatherly, D. B., Laucella, S. A., Cabinian, M. A., Crim, M. T., Sullivan, S., et al. (2006). CD8+ T-Cell Responses to Trypanosoma Cruzi Are Highly Focused on Strain-Variant Trans-Sialidase Epitopes. PloS Pathog. 2, e77. doi: 10.1371/journal.ppat.0020077

Moody, A. M., Chui, D., Reche, P. A., Priatel, J. J., Marth, J. D., and Reinherz, E. L. (2001). Developmentally Regulated Glycosylation of the CD8alphabeta Coreceptor Stalk Modulates Ligand Binding. Cell 107, 501-512. doi: 10.1016/ S0092-8674(01)00577-3

Mor, G., Klinman, D. M., Shapiro, S., Hagiwara, E., Sedegah, M., Norman, J. A., et al. (1995). Complexity of the Cytokine and Antibody Response Elicited by Immunizing Mice With Plasmodium Yoelii Circumsporozoite Protein Plasmid DNA. J. Immunol. 155, 2039-2046.

Morrot, A., and Zavala, F. (2004). Effector and Memory CD8+ T Cells as Seen in Immunity to Malaria. Immunol. Rev. 201, 291-303. doi: 10.1111/j.01052896.2004.00175.x

Mucci, J., Hidalgo, A., Mocetti, E., Argibay, P. F., Leguizamon, M. S., and Campetella, O. (2002). Thymocyte Depletion in Trypanosoma Cruzi Infection Is Mediated by Trans-Sialidase-Induced Apoptosis on Nurse Cells Complex. Proc. Natl. Acad. Sci. U. S. A. 99, 3896-3901. doi: 10.1073/ pnas.052496399

Mucci, J., Mocetti, E., Leguizamon, M. S., and Campetella, O. (2005). A Sexual Dimorphism in Intrathymic Sialylation Survey Is Revealed by the TransSialidase From Trypanosoma Cruzi. J. Immunol. 174, 4545-4550. doi: 10.4049/ jimmunol.174.8.4545

Mucci, J., Risso, M. G., Leguizamon, M. S., Frasch, A. C., and Campetella, O. (2006). The Trans-Sialidase From Trypanosoma Cruzi Triggers Apoptosis by Target Cell Sialylation. Cell Microbiol. 8, 1086-1095. doi: 10.1111/j.14625822.2006.00689.x

Murali-Krishna, K., Altman, J. D., Suresh, M., Sourdive, D. J., Zajac, A. J., Miller, J. D., et al. (1998). Counting Antigen-Specific CD8 T Cells: A Reevaluation of Bystander Activation During Viral Infection. Immunity 8, 177-187. doi: 10.1016/S1074-7613(00)80470-7

Nardy, A. F., Freire-De-Lima, C. G., Perez, A. R., and Morrot, A. (2016). Role of Trypanosoma Cruzi Trans-Sialidase on the Escape From Host Immune Surveillance. Front. Microbiol. 7, 348. doi: 10.3389/fmicb.2016.00348

Nunes, M. P., Fortes, B., Silva-Filho, J. L., Terra-Granado, E., Santos, L., Conde, L., et al. (2013). Inhibitory Effects of Trypanosoma Cruzi Sialoglycoproteins on CD4+ T Cells Are Associated With Increased Susceptibility to Infection. PloS One 8, e77568. doi: 10.1371/journal.pone.0077568
Oladiran, A., and Belosevic, M. (2012). Immune Evasion Strategies of Trypanosomes: A Review. J. Parasitol. 98, 284-292. doi: 10.1645/GE-2925.1

Pereira-Chioccola, V. L., Costa, F., Ribeirao, M., Soares, I. S., Arena, F., Schenkman, S., et al. (1999). Comparison of Antibody and Protective Immune Responses Against Trypanosoma Cruzi Infection Elicited by Immunization With a Parasite Antigen Delivered as Naked DNA or Recombinant Protein. Parasite Immunol. 21, 103-110. doi: 10.1046/j.13653024.1999.00201.x

Pereira, M. E., Loures, M. A., Villalta, F., and Andrade, A. F. (1980). Lectin Receptors as Markers for Trypanosoma Cruzi. Developmental Stages and a Study of the Interaction of Wheat Germ Agglutinin With Sialic Acid Residues on Epimastigote Cells. J. Exp. Med. 152, 1375-1392. doi: 10.1084/ jem.152.5.1375

Pereira, K. S., Schmidt, F. L., Guaraldo, A. M., Franco, R. M., Dias, V. L., and Passos, L. A. (2009). Chagas' Disease as a Foodborne Illness. J. Food Prot 72, 441-446. doi: 10.4315/0362-028X-72.2.441

Pollevick, G. D., Affranchino, J. L., Frasch, A. C., and Sanchez, D. O. (1991). The Complete Sequence of a Shed Acute-Phase Antigen of Trypanosoma Cruzi. Mol. Biochem. Parasitol. 47, 247-250. doi: 10.1016/0166-6851(91)90185-9

Previato, J. O., Andrade, A. F., Pessolani, M. C., and Mendonca-Previato, L. (1985). Incorporation of Sialic Acid Into Trypanosoma Cruzi Macromolecules. A Proposal for a New Metabolic Route. Mol. Biochem. Parasitol. 16, 85-96. doi: 10.1016/0166-6851(85)90051-9

Previato, J.O.A., A.F.B., Vermelho, A., Firmino, J. C., and Mendonça-Previato, L. (1990). Evidence for N-Glycolylneuraminic Acid Incorporation by Trypanosoma Cruzi From Infected Animal. Mem Inst. Oswaldo Cruz 85, 38-39.

Prochetto, E., Roldan, C., Bontempi, I. A., Bertona, D., Peverengo, L., Vicco, M. H., et al. (2017). Trans-Sialidase-Based Vaccine Candidate Protects Against Trypanosoma Cruzi Infection, Not Only Inducing an Effector Immune Response But Also Affecting Cells With Regulatory/Suppressor Phenotype. Oncotarget 8, 58003-58020. doi: 10.18632/oncotarget.18217

Ramirez, J. L. (2019). An Evolutionary View of Trypanosoma Cruzi Telomeres. Front. Cell Infect. Microbiol. 9, 439. doi: 10.3389/fcimb.2019.00439

Reis-Cunha, J. L., Valdivia, H. O., and Bartholomeu, D. C. (2018). Gene and Chromosomal Copy Number Variations as an Adaptive Mechanism Towards a Parasitic Lifestyle in Trypanosomatids. Curr. Genomics 19, 87-97. doi: $10.2174 / 1389202918666170911161311$

Richards, D. M., Delacher, M., Goldfarb, Y., Kagebein, D., Hofer, A. C., Abramson, J., et al. (2015). Treg Cell Differentiation: From Thymus to Peripheral Tissue. Prog. Mol. Biol. Transl. Sci. 136, 175-205. doi: 10.1016/bs.pmbts.2015.07.014

Risso, M. G., Pitcovsky, T. A., Caccuri, R. L., Campetella, O., and Leguizamon, M. S. (2007). Immune System Pathogenesis Is Prevented by the Neutralization of the Systemic Trans-Sialidase From Trypanosoma Cruzi During Severe Infections. Parasitology 134, 503-510. doi: 10.1017/S0031182006001752

Rock, K. L., and Shen, L. (2005). Cross-Presentation: Underlying Mechanisms and Role in Immune Surveillance. Immunol. Rev. 207, 166-183. doi: 10.1111/ j.0105-2896.2005.00301.x

Rodrigues, M. M., Ribeirao, M., Pereira-Chioccola, V., Renia, L., and Costa, F. (1999). Predominance of CD4 Th1 and CD8 Tc1 Cells Revealed by Characterization of the Cellular Immune Response Generated by Immunization With a DNA Vaccine Containing a Trypanosoma Cruzi Gene. Infect. Immun. 67, 3855-3863. doi: 10.1128/IAI.67.8.3855-3863.1999

Rodriguez-Morales, O., Monteon-Padilla, V., Carrillo-Sanchez, S. C., Rios-Castro, M., Martinez-Cruz, M., Carabarin-Lima, A., et al. (2015). Experimental Vaccines Against Chagas Disease: A Journey Through History. J. Immunol. Res. 2015, 489758. doi: 10.1155/2015/489758

Rosenberg, C. S., Martin, D. L., and Tarleton, R. L. (2010). CD8+ T Cells Specific for Immunodominant Trans-Sialidase Epitopes Contribute to Control of Trypanosoma Cruzi Infection But Are Not Required for Resistance. J. Immunol. 185, 560-568. doi: 10.4049/jimmunol.1000432

Ruiz Diaz, P., Mucci, J., Meira, M. A., Bogliotti, Y., Musikant, D., Leguizamon, M. S., et al. (2015). Trypanosoma Cruzi Trans-Sialidase Prevents Elicitation of Th1 Cell Response via Interleukin 10 and Downregulates Th1 Effector Cells. Infect. Immun. 83, 2099-2108. doi: 10.1128/IAI.00031-15

Salazar, R., Castillo-Neyra, R., Tustin, A. W., Borrini-Mayori, K., Naquira, C., and Levy, M. Z. (2015). Bed Bugs (Cimex Lectularius) as Vectors of Trypanosoma Cruzi. Am. J. Trop. Med. Hyg. 92, 331-335. doi: 10.4269/ajtmh.14-0483 
Schalk, J. A., Mooi, F. R., Berbers, G. A., Van Aerts, L. A., Ovelgonne, H., and Kimman, T. G. (2006). Preclinical and Clinical Safety Studies on DNA Vaccines. Hum. Vaccin. 2, 45-53. doi: 10.4161/hv.2.2.2620

Schauer, R., Reuter, G., Muhlpfordt, H., Andrade, A. F., and Pereira, M. E. (1983). The Occurrence of N-Acetyl- and N-Glycoloylneuraminic Acid in Trypanosoma Cruzi. Hoppe Seylers Z Physiol. Chem. 364, 1053-1057. doi: 10.1515/bchm2.1983.364.2.1053

Schenkman, S., Jiang, M. S., Hart, G. W., and Nussenzweig, V. (1991). A Novel Cell Surface Trans-Sialidase of Trypanosoma Cruzi Generates a Stage-Specific Epitope Required for Invasion of Mammalian Cells. Cell 65, 1117-1125. doi: 10.1016/0092-8674(91)90008-M

Schenkman, R. P., Vandekerckhove, F., and Schenkman, S. (1993). Mammalian Cell Sialic Acid Enhances Invasion by Trypanosoma Cruzi. Infect. Immun. 61, 898-902. doi: 10.1128/iai.61.3.898-902.1993

Sedegah, M., Hedstrom, R., Hobart, P., and Hoffman, S. L. (1994). Protection Against Malaria by Immunization With Plasmid DNA Encoding Circumsporozoite Protein. Proc. Natl. Acad. Sci. U. S. A. 91, 9866-9870. doi: 10.1073/pnas.91.21.9866

Sepulveda, P., Hontebeyrie, M., Liegeard, P., Mascilli, A., and Norris, K. A. (2000). DNA-Based Immunization With Trypanosoma Cruzi Complement Regulatory Protein Elicits Complement Lytic Antibodies and Confers Protection Against Trypanosoma Cruzi Infection. Infect. Immun. 68, 4986-4991. doi: 10.1128/ IAI.68.9.4986-4991.2000

Short, E. E., Caminade, C., and Thomas, B. N. (2017). Climate Change Contribution to the Emergence or Re-Emergence of Parasitic Diseases. Infect. Dis. (Auckl) 10, 1178633617732296. doi: 10.1177/1178633617732296

Silva-Barrios, S., Charpentier, T., and Stager, S. (2018). The Deadly Dance of B Cells With Trypanosomatids. Trends Parasitol. 34, 155-171. doi: 10.1016/ j.pt.2017.10.001

Stills, H. F.Jr. (2005). Adjuvants and Antibody Production: Dispelling the Myths Associated With Freund's Complete and Other Adjuvants. ILAR J. 46, 280293. doi: 10.1093/ilar.46.3.280

Sui, Y., Hogg, A., Wang, Y., Frey, B., Yu, H., Xia, Z., et al. (2014). Vaccine-Induced Myeloid Cell Population Dampens Protective Immunity. J. Clin. Invest. 124, 2538-2549. doi: 10.1172/JCI73518

Suschak, J. J., Williams, J. A., and Schmaljohn, C. S. (2017). Advancements in DNA Vaccine Vectors, Non-Mechanical Delivery Methods, and Molecular Adjuvants to Increase Immunogenicity. Hum. Vaccin. Immunother. 13, 28372848. doi: 10.1080/21645515.2017.1330236

Teixeira, A. A., De Vasconcelos Vde, C., Colli, W., Alves, M. J., and Giordano, R. J. (2015). Trypanosoma Cruzi Binds to Cytokeratin Through Conserved Peptide Motifs Found in the Laminin-G-Like Domain of the Gp85/Trans-Sialidase Proteins. PloS Negl. Trop. Dis. 9, e0004099. doi: 10.1371/journal.pntd.0004099

Todeschini, A. R., Girard, M. F., Wieruszeski, J. M., Nunes, M. P., Dosreis, G. A., Mendonca-Previato, L., et al. (2002a). Trans-Sialidase From Trypanosoma Cruzi Binds Host T-Lymphocytes in a Lectin Manner. J. Biol. Chem. 277, 45962-45968. doi: 10.1074/jbc.M203185200

Todeschini, A. R., Nunes, M. P., Pires, R. S., Lopes, M. F., Previato, J. O., Mendonca-Previato, L., et al. (2002b). Costimulation of Host T Lymphocytes by a Trypanosomal Trans-Sialidase: Involvement of CD43 Signaling. J. Immunol. 168, 5192-5198. doi: 10.4049/jimmunol.168.10.5192

Tribulatti, M. V., Mucci, J., Van Rooijen, N., Leguizamon, M. S., and Campetella, O. (2005). The Trans-Sialidase From Trypanosoma Cruzi Induces Thrombocytopenia During Acute Chagas' Disease by Reducing the Platelet Sialic Acid Contents. Infect. Immun. 73, 201-207. doi: 10.1128/IAI.73.1.201-207.2005

Tzelepis, F., De Alencar, B. C., Penido, M. L., Claser, C., Machado, A. V., BrunaRomero, O., et al. (2008). Infection With Trypanosoma Cruzi Restricts the Repertoire of Parasite-Specific CD8+ T Cells Leading to Immunodominance. J. Immunol. 180, 1737-1748. doi: 10.4049/jimmunol.180.3.1737
Vasconcelos, J. R., Boscardin, S. B., Hiyane, M. I., Kinoshita, S. S., Fujimura, A. E., and Rodrigues, M. M. (2003). A DNA-Priming Protein-Boosting Regimen Significantly Improves Type 1 Immune Response But Not Protective Immunity to Trypanosoma Cruzi Infection in a Highly Susceptible Mouse Strain. Immunol. Cell Biol. 81, 121-129. doi: 10.1046/j.0818-9641.2002.01136.x

Vazquez-Jimenez, L. K., Paz-Gonzalez, A. D., Juarez-Saldivar, A., Uhrig, M. L., Agusti, R., Reyes-Arellano, A., et al. (2021). Structure-Based Virtual Screening of New Benzoic Acid Derivatives as Trypanosoma Cruzi Trans-Sialidase Inhibitors. Med. Chem. 17, 724-731. doi: 10.2174/1573406416666200506084611

Vetter, V., Denizer, G., Friedland, L. R., Krishnan, J., and Shapiro, M. (2018). Understanding Modern-Day Vaccines: What You Need to Know. Ann. Med. 50, 110-120. doi: 10.1080/07853890.2017.1407035

World Health Organization. (2017). Integrating Neglected Tropical Diseases Into Global Health and Development. Fourth WHO Rep. Negl. Trop. Dis. 4:1-269.

Xu, D., and Liew, F. Y. (1995). Protection Against Leishmaniasis by Injection of DNA Encoding a Major Surface Glycoprotein, Gp63, of L. Major. Immunology 84, 173-176.

Yaseen, M. M., Abuharfeil, N. M., Darmani, H., and Daoud, A. (2021). Recent Advances in Myeloid-Derived Suppressor Cell Biology. Front. Med. 15, 232251. doi: 10.1007/s11684-020-0797-2

Yoshida, N., Tyler, K. M., and Llewellyn, M. S. (2011). Invasion Mechanisms Among Emerging Food-Borne Protozoan Parasites. Trends Parasitol. 27, 459466. doi: 10.1016/j.pt.2011.06.006

Zingales, B. (2018). Trypanosoma Cruzi Genetic Diversity: Something New for Something Known About Chagas Disease Manifestations, Serodiagnosis and Drug Sensitivity. Acta Trop. 184, 38-52. doi: 10.1016/j.actatropica.2017.09.017

Zingales, B., Andrade, S. G., Briones, M. R., Campbell, D. A., Chiari, E., Fernandes, O., et al. (2009). A New Consensus for Trypanosoma Cruzi Intraspecific Nomenclature: Second Revision Meeting Recommends TcI to TcVI. Mem Inst. Oswaldo Cruz 104, 1051-1054. doi: 10.1590/S0074-02762009000700021

Zingales, B., Carniol, C., De Lederkremer, R. M., and Colli, W. (1987). Direct Sialic Acid Transfer From a Protein Donor to Glycolipids of Trypomastigote Forms of Trypanosoma Cruzi. Mol. Biochem. Parasitol. 26, 135-144. doi: 10.1016/ 0166-6851(87)90137-X

Zingales, B., Miles, M. A., Campbell, D. A., Tibayrenc, M., Macedo, A. M., Teixeira, M. M., et al. (2012). The Revised Trypanosoma Cruzi Subspecific Nomenclature: Rationale, Epidemiological Relevance and Research Applications. Infect. Genet. Evol. 12, 240-253. doi: 10.1016/j.meegid. 2011.12.009

Conflict of Interest: The authors declare that the research was conducted in the absence of any commercial or financial relationships that could be construed as a potential conflict of interest.

Publisher's Note: All claims expressed in this article are solely those of the authors and do not necessarily represent those of their affiliated organizations, or those of the publisher, the editors and the reviewers. Any product that may be evaluated in this article, or claim that may be made by its manufacturer, is not guaranteed or endorsed by the publisher.

Copyright (ㄷ 2021 da Costa, Marques da Fonseca, dos Reis, Santos, Previato, Mendonç-Previato and Freire-de-Lima. This is an open-access article distributed under the terms of the Creative Commons Attribution License (CC BY). The use, distribution or reproduction in other forums is permitted, provided the original author(s) and the copyright owner(s) are credited and that the original publication in this journal is cited, in accordance with accepted academic practice. No use, distribution or reproduction is permitted which does not comply with these terms. 